\title{
Ebstein's Anomaly With Imperforate Tricuspid Valve. Prenatal Diagnosis
}

\author{
Paulo Zielinsky, Carlo B. Pilla
}

Porto Alegre, RS - Brazil

\begin{abstract}
Ebstein's anomaly is an uncommon congenital heart defect, with a prevalence of $0.3-0.5 \%$. Its association with an imperforate tricuspid valve is an even more rare situation (less than $10 \%$ of cases). Prenatal diagnosis of this association by means of fetal echocardiography has not been reported. We describe here this association diagnosed before birth and confirmed after birth. The diagnostic potential and importance of fetal echocardiography during prenatal evaluation of cardiac malformations allows for adequate perinatal planning and management, with an obvious impact on morbidity and mortality.
\end{abstract}

Ebstein's anomaly is an uncommon congenital heart defect with an approximate prevalence of $0.3-0.5 \%$ of all cardiac malformations ${ }^{1,2}$.

Prenatal diagnosis of this anomaly has been possible through the development of fetal echocardiography. The rare association of Ebstein's anomaly with an imperforate tricuspid valve has not yet been described during intrauterine life.

This report describes for the first time the diagnosis of Ebstein's anomaly with imperforation of the tricuspid valve in a fetus documented with fetal echocardiography.

\section{Case Report}

The patient is a single male fetus of a healthy 29 year old woman who had a normal pregnancy and an uneventful prenatal period. No history existed of either potentially teratogenic drug consumption any time during pregnancy or of congenital heart disease. The mother underwent regular prenatal checks in her hometown where the cardiac alteration was detected during obstetrical ultrasonography. She was referred to the Fetal Cardiology Unit for evaluation. At that time gestation was at 36 weeks. Fetal echocardiography revealed Ebstein's anomaly of the tricuspid valve, which was imperforate, not allowing passage of flow from the right atrium to the right ventricle. A morphologic

Instituto de Cardiologia do Rio Grande do Sul - Fundação Universitária de Cardiologia - Porto Alegre

Mailing address: Paulo Zielinsky - Instituto de Cardiologia do RS - Av. Princesa Isabel, 395 - 90620-001 - Porto Alegre - RS - Brazil arrangement like this-corresponded functionally to tricuspid atresia (figures 1,2 and 3).

After birth, sequential echocardiograms confirmed the presence of Ebstein's anomaly with imperforation of the tricuspid valve. A gradual restriction of flow through the ventricular septal defect was observed, which resulted in progressive cyanosis in the patient. The beginning of functional atresia was observed, requiring the interposition of a conduit between the subclavicular and pulmonary arteries to increase the pulmonary flow and alleviate hypoxemia. Surgery was carried out at 45 days of life.

\section{Discussion}

Ebstein's anomaly is characterized by a caudal displacement of septal and posterior leaflets of the tricuspid valve, as well as its distal insertions. These leaflets normally are dysplastic, redundant and adhered to the right ventricle wall ${ }^{1-5}$. Anomalies may also occur in the chordae tendinea. This anatomic condition leads to a decrease in the of dimensions of the functional right ventricle, which becomes restricted to the trabecular and outlet zones. The inlet zone is located above the valvar ring and is known as the atrialized right ventricle, with thinner walls and being partially responsible for defective filling of the ventricle, one of the causes of hemodynamic disturbances ${ }^{2}$.

The natural evolution depends on the severity of the defect, as the range of anomalies is large. In the less severe cases, patients are asymptomatic, but in the more severe ones cardiac insufficiency and cyanosis occur in the first weeks, with a tendency to improve as pulmonary vascular resistance diminishes. Eventually, a return to previous conditions occurs, with dyspnea on exertion and to cyanosis either low output or right to left atrial shunt, or both.

The following anomalies have been reported that may be associated with Ebstein's anomaly: atrial septal defect $(90 \%)$, anatomic or functional pulmonary atresia $(30 \%)$ and ventricular septal defect (less common) ${ }^{1-3}$.

In about $10 \%$ of cases, the tricuspid valve is imperforate, leading to functional tricuspid atresia ${ }^{2,5}$. This imperforation occurs due to the excessive redundancy of the anterior leaflet, with fusion of the comissures, obstructing the passage of flow from the right atrium to the right ventricle. 


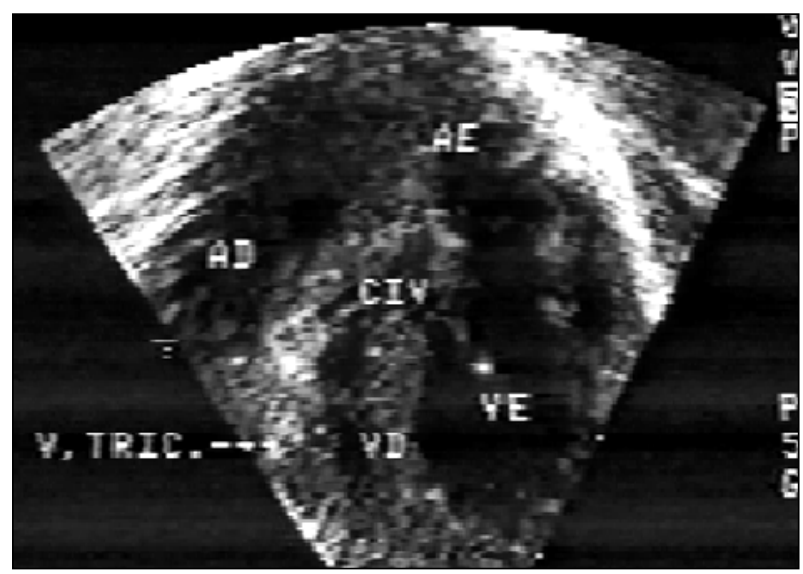

Fig.1 - Cut demonstrating caudal displacement of tricuspid valve and interventricular communication.

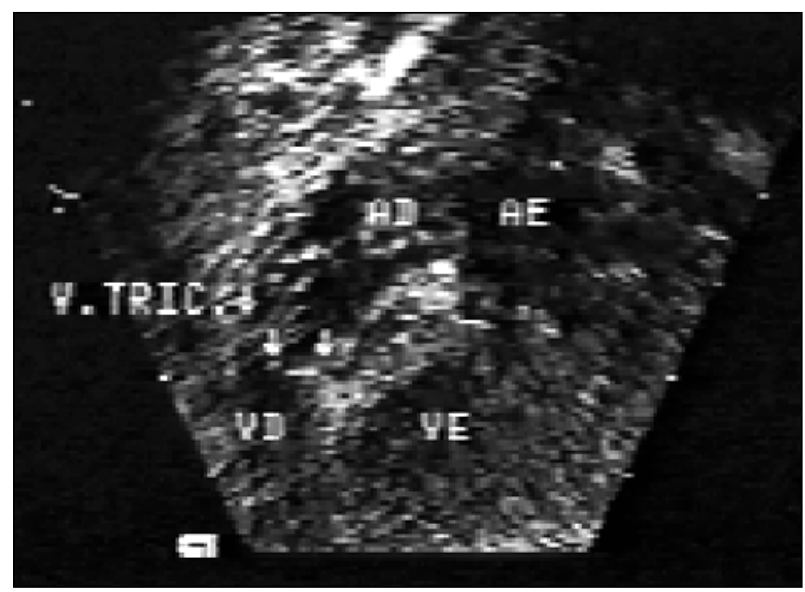

Fig. 2 - Cut demonstrating caudal displacement of tricuspid valve.

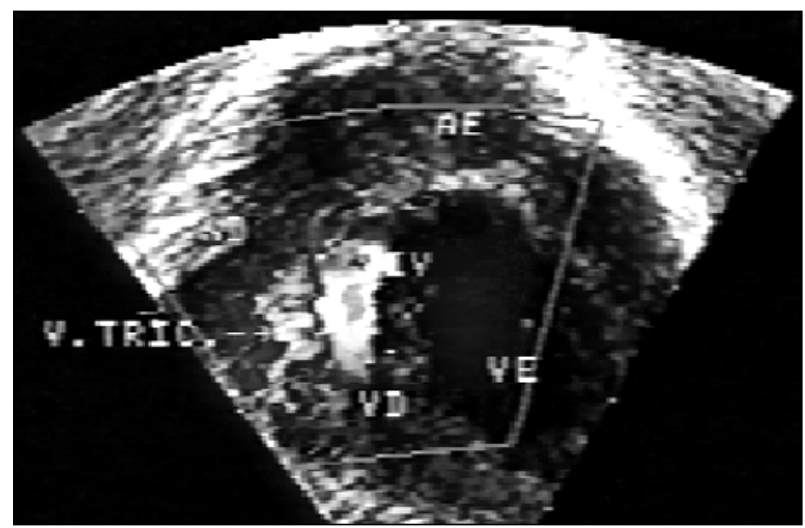

Fig. 3 - Cut demonstrating through color-Doppler, flow from left ventricle to right ventricle.

This anatomic condition has been and continues to be the subject of discussion, as functionally it may be classified as
Ebstein's anomaly with imperforate tricuspid valve

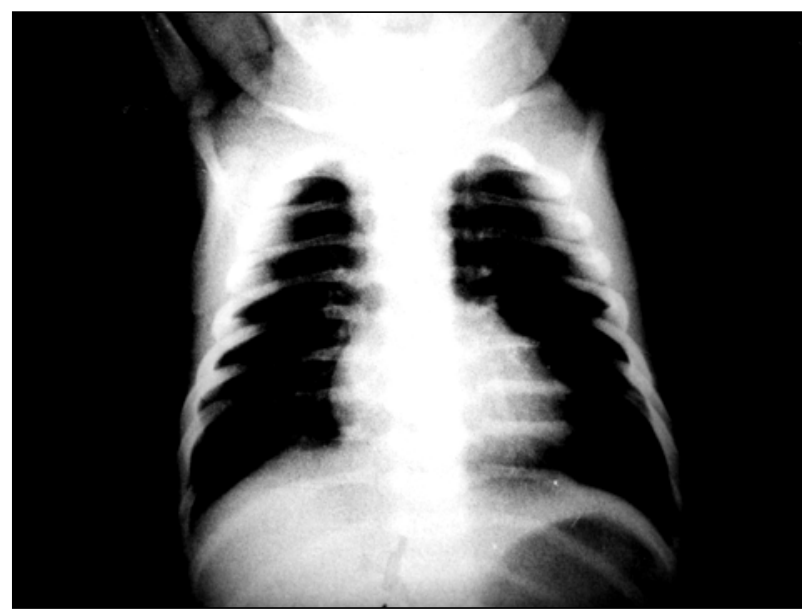

Fig. 4 - Chest X-ray demonstrating cardiomegaly and severe pulmonary hypoflow.

a subtype of tricuspid atresia, but embryologically it belongs to the spectrum of Ebstein's anomaly ${ }^{3-6}$. The first cases were described in anatomic specimens by Van Praagh et al in $1971^{7}$.

The association of Ebstein's anomaly with imperforate valve and pulmonary atresia is an even more rare condition, the first two cases having been described in 1976 and $1977^{6}$.

The diagnosis and monitoring of tricuspid valve anomalies, such as Ebstein's anomaly and valvar dysplasia, during uterine life have shown that a potential exists for the development of obstructive lesions of the right ventricle (critical pulmonary stenosis and pulmonary atresia). This factor is associated with a poor postnatal prognosis ${ }^{8,9}$.

At the present time, no reports of the diagnosis of Ebstein's anomaly with imperforate valve in the prenatal period using fetal echocardiography have been found. In a series of 7,000 fetuses examined during a 10 year period, 14 cases of Ebstein's anomaly were identified; however, in no one of these cases' valve imperforation and absence of flow from the right atrium to the left ventricle ${ }^{9}$ has been reported.

The case here reported focuses not only on the characteristic image of dysplasia and caudal displacement of the tricuspid valve, but also on the absence of right atrioventricular flow, in spite of the movement of the leaflets, thus documenting the imperforate valve.

Prenatal diagnosis of this anomaliys was decisive in the management of the patient, as its birth could be planned to take place in an adequately prepared, environment from a cardiological point of view.

This report demonstrates the potential of fetal echocardiography in detection of rare defects, with an important impact on perinatal cardiologic management. 


\section{References}

1. Anderson RH, Shinebourne EA, Macartney FJ, Tynan M. Ebstein's malformation and related lesions of the tricuspid valve. Paediatric Cardiology 1987: 721-36.

2. MacLellan-Tobert SJ, Porter CBJ. Ebstein's anomaly of the tricuspid valve. In: Garson AJ, Bricker JT, Fisher DJ, Neish SR. The Science and Practice of Pediatric Cardiology. $2^{\text {nd }}$ Ed. Lea \& Febiger Cidade: Philadelphia Editora, 1998: 1303.

3. Rao PS, Jue KL, Isabel-Jones J, Ruttenberg HD. Ebstein's malformation of the tricuspid valve with atresia - Differentiation from isolated tricuspid atresia. Am J Cardiol 1973; 32: 1004-9.

4. Zuberbuhler JR, Allwork SP, Anderson RH. The spectrum of Ebstein's anomaly of the tricuspid valve. J Thorac Cardiovasc Surg 1979; 77: 202-11.
5. Anderson KR, Zuberbuhler JR, Anderson RH, Becker AE, Lie JT. Morphologic spectrum of Ebstein's anomaly of the heart - a review. Mayo Clinics Proc 1979; 54: $174-80$.

6. Anderson RH, Wilkinson JL, Gerlis LM, Smith A, Becker AE. Atresia of the right atrioventricular orifice. Br Heart J 1977; 39: 414-28.

7. Van Praagh R, Ando M, Dungan WT. Anatomic types of tricuspid atresia: clinical and development implications. Circulation 1971; 43 and 44: II-115.

8. Roberson DA, Silverman NH. Ebstein's anomaly: Echocardiographic and clinical features in the fetus and neonate. J Am Coll Cardiol 1989; 14: 1300-7.

9. Sharland GK, Chita SK, Allan LD. Tricuspid valve dysplasia or displacement in intrauterine life. J Am Coll Cardiol 1991; 17: 944-9. 